\title{
Gender Issues in Clinical Dental Education
}

\author{
Karen K. Tiwana, D.D.S.; Mark J. Kutcher, D.D.S., M.S.; Ceib Phillips, M.P.H., Ph.D.; \\ Margot Stein, Ph.D.; Jessica Oliver, D.D.S.
}

Abstract: In spring 2011, a study was initiated to investigate the nature and extent of gender issues in clinical dental education at the University of North Carolina at Chapel Hill School of Dentistry. Surveys were sent to 236 dental students in the second, third, and fourth years; eighty-six (36.4 percent) responded. Surveys were also sent to seventy-one full-time dental faculty members who had clinical contact with students, and thirty-four (47.9 percent) responded. Of the student respondents, fifty-one were female and thirty-five were male; the faculty respondents were ten women and twenty-four men. A significantly greater proportion of female than male student respondents reported that issues related to gender affected clinical training. The female students also responded that mentorship was less available and less in content for them compared to males, and significantly more female than male students reported lower self-confidence in clinical settings. Among faculty respondents, a higher proportion of women than men reported insufficient awareness of gender issues. These faculty members also reported thinking that female students showed more empathy toward patients than males. Both faculty and student respondents said that female faculty members received less respect from students than did male faculty members. Forty-eight percent of the students reported experiencing or witnessing genderbased prejudice in clinical settings, and 7.0 percent reported experiencing or witnessing unwelcome sexual advances or conduct. A more robust study to include other dental institutions is needed. With confirmation of specific gender issues, corrective measures could be recommended to improve the climate for both females and males in the clinical component of dental education.

Dr. Tiwana is Clinical Assistant Professor, Department of Operative Dentistry, School of Dentistry, University of North Carolina at Chapel Hill; Dr. Kutcher is Associate Professor of Oral Medicine, Department of Dental Ecology, School of Dentistry, University of North Carolina at Chapel Hill; Dr. Phillips is Professor, Department of Orthodontics and Assistant Dean for Graduate/ Advanced Education, University of North Carolina at Chapel Hill; Dr. Stein is Clinical Associate Professor, Department of Dental Ecology, School of Dentistry, University of North Carolina at Chapel Hill; and Dr. Oliver is in private practice in Wadesboro, North Carolina. Direct correspondence and requests for reprints to Dr. Karen K. Tiwana, Department of Operative Dentistry, School of Dentistry, University of North Carolina, 5405H Kory Oral Health Sciences Building, CB\#7455, Chapel Hill, NC 27599-7455; 919-537-3146; karen_tiwana@unc.edu.

Keywords: dental education, clinical dental education, gender issues, dental faculty, dental students, women in dental education, behavioral science

Submitted for publication 2/12/13; accepted 6/18/13

$\mathrm{G}$ iven the major influx of women into the health professions over the past four decades, gender differences in workplace experiences have become an important focus of research. Attempts to examine the impact of gender differences during professional training are more recent, with medical school and health care settings as the primary foci of concern. ${ }^{1-3}$ However, the effects of this major demographic change and perceptions of male and female students and faculty in dental schools have not been extensively researched, especially as pertains to the clinical component of dental education. ${ }^{1}$

Before the early 1970s, dentists were almost exclusively male. ${ }^{2}$ Although a combination of legal, social, and cultural changes in the United States in the 1960s and 1970s made dental school more accessible to women, it took years for the number of male and female dental students to become more equitable. In 1975, only 3.2 percent of the students in U.S. dental classes were women. By 1997, this number had jumped to 36.5 percent, and today more than 40 percent of dental school students are women. ${ }^{2}$
The ratio of male to female faculty members also has changed over time, albeit much more slowly. The American Dental Association currently estimates that 78 percent of U.S. dental faculty members are male and 22 percent are female. ${ }^{3}$ Despite the low proportion of female dental faculty members, women in dental education are more likely to have full-time faculty positions than are their male colleagues. ${ }^{4,5}$ With the rising number of female dental students, the number of women on dental faculties will likely continue to increase with time as well. ${ }^{5}$

Although gender issues in clinical medical education have been discussed for years, ${ }^{6-9}$ the dental literature in these domains, especially based on research studies, is scant. Such concepts as professional and gender roles held by male and female dental students, ${ }^{10}$ the relationship between gender and postgraduate dental aspirations, ${ }^{11}$ and unequal treatment and sexual harassment experienced by female dental hygiene students ${ }^{12}$ have been explored in the dental literature. However, gender issues that exist among dental students and faculty members 
in the clinical education setting remain unexplored. Perceptions of gender difference have implications for the future direction of dental education and the effective delivery of dental care. The objective of this study was to explore the perception of gender issues among students and faculty members during clinical dental education at our institution.

\section{Materials and Methods}

Gender issues in clinical dental education at the University of North Carolina at Chapel Hill School of Dentistry were assessed using two approaches: structured interviews and a survey of students and faculty. A "gender issue" was defined as "any experience in a clinical dental education setting where gender is perceived to play a meaningful role." This study received full approval from the university's Institutional Review Board.

To first identify pertinent gender issues to be assessed in the survey instruments, structured interviews were held with both students and faculty members. Ten interviews with members of each class (five female, five male) were considered sufficient to provide adequate diversity of opinion; ${ }^{13}$ therefore, five male and five female dental students from the second-, third-, and fourth-year classes were randomly selected and invited to participate in confidential individual interviews. Of the thirty students, none declined to participate. First-year dental students were excluded because their curriculum to that point was primarily didactic with little clinical exposure. Clinical faculty members were sorted by department, and convenience sampling was used to select five women and five men, randomly selected from various departments, who had significant weekly student contact. The small number of full-time female clinical faculty members at our institution limited the ability to meaningfully randomly select for invitation to participate in the individual interviews. None of the faculty members who were invited to participate declined.

Individual interviews were arranged at a mutually convenient time and location. After obtaining consent, the interview leader followed a script for discussion with each interviewee. The interviews took place in a private setting and were completely confidential. They were conducted by Jessica Oliver, a fourth-year dental student and research fellow who was trained to give the interviews; she followed a predesigned open-ended script that was constructed by the authors. The interviewer recorded the interviewee's perspectives in writing using a unique identifier to maintain confidentiality.

After review of all the responses, the responses were pooled, and common themes and trends relating to any relevant gender issues in the clinical education setting were identified. Following identification of recurring themes, survey items were constructed that encompassed those themes. A twenty-one item survey for the students and a seventeen-item survey for the faculty, both of which included checkbox and open-ended questions, were created. The survey items were reviewed for content validity, readability, and structure by five selected faculty members and five dental students.

Surveys were administered in the spring of 2011 using Qualtrics (Qualtrics Research Suite, version 2011; Qualtrics Labs, Inc., Provo, UT) to all dental students and full-time faculty members via their dental school email addresses. The study focused on only predoctoral dental students; all residents and graduate students were excluded from the study. The email contained a brief description of the study, a statement regarding anonymity and implied consent, and a link to the appropriate survey. The emails were sent every two weeks over a six-week period to obtain maximum participation. Because of the time of year, the survey was emailed a fourth time to the sophomore and junior students. The survey software prevented respondents from taking the survey more than once.

After the surveys were completed, data were analyzed using Fisher's Exact Test. Continuous data were categorized. Analyses were performed within each respondent group (students and faculty). For each group, the responses for the confidence and perception items were compared between males and females using Fisher's Exact Test. A p-value of $<0.05$ was considered statistically significant. The outcome variables were confidence and perception items of respondent group's students and faculty. The explanatory variable was gender. All analysis was performed using SAS v9.1.

\section{Results}

A total of 236 surveys were sent to dental students in the sophomore $(n=78)$, junior $(n=78)$, and senior $(\mathrm{n}=80)$ classes. Eighty-six students $(36.4$ percent) responded: twenty-eight sophomores, thirtyfour juniors, and twenty-four seniors. In addition, sur- 
veys were sent to seventy-one full-time dental faculty members who had clinical contact with students. Of the faculty members who responded, thirty-four (47.9 percent) reported having interaction with students in a clinical setting.

Of the eighty-six student respondents, fiftyone (59 percent) were female, and the vast majority were Caucasian ( $n=63,73$ percent). Of the thirty-four faculty members who had clinical interactions with D.D.S. students, ten were female (29 percent), and most ( $\mathrm{n}=21,62$ percent) were Caucasian. The age distribution of the faculty respondents was as follows: thirty-five to forty-five years, $n=11$; forty-six to fiftyfive years, $n=4$; and fifty-six to seventy-five years, $\mathrm{n}=17$ (three participants did not answer). Faculty members reported spending one to eight half-days in the clinic during a typical week.

\section{Perceptions of Students vs. Faculty}

Female students reported feeling less confident compared with their classmates in clinical settings than did male students: 74 percent of the males but only 45 percent of the females expressed a high degree of self-confidence $(p<0.001)$. In contrast, faculty members perceived no significant difference between male and female students in the preparation for and confidence in performing clinical procedures. In addition, both students and faculty members reported no significant differences in clinical abilities by gender at any given time point during the students' education. These students generally indicated no preference to working with female versus male faculty members. Likewise, 100 percent of the faculty respondents reported no gender preference when working with students in the clinical setting. However, significantly more students thought that students showed less respect to female faculty members than to male faculty members $(p<0.001)$. The female faculty respondents, but not the male faculty respondents, agreed with this assessment $(\mathrm{p}=0.007)$.

Almost 48 percent of the students reported personally experiencing or witnessing gender-related prejudice (in action or treatment) against a peer in a clinical setting. Part-time faculty members were listed as the most frequent offenders $(n=23)$, followed by full-time faculty members $(n=17)$, graduate teaching assistants $(n=13)$, peers $(n=11)$, patients $(n=10)$, and staff members $(n=7)$. In contrast, only 15 percent of the faculty respondents reported personally witnessing any gender-related prejudice toward students by faculty in the clinical setting. In addition, six stu- dents ( 7 percent) reported personally experiencing or witnessing unwelcome sexual advances or conduct (verbal or nonverbal) from faculty members. Four faculty members (11.8 percent) likewise reported witnessing unwelcome sexual advances or conduct by faculty members toward students.

Most students (81 percent) reported thinking faculty members were sensitive to gender issues overall, although 37 percent noted that younger faculty members were more sensitive than older faculty members in this regard. However, amongst faculty respondents, a significantly higher proportion of females ( 56 percent) than males (12 percent) responded that there was not appropriate awareness and insight into issues regarding gender $(\mathrm{p}=0.017)$. In addition, 39.5 percent of the students reported a difference in verbal or nonverbal communication when faculty members spoke with female versus male students. In contrast, 88 percent of the faculty members reported no difference in their communications by student gender. Both students and faculty members perceived female students to be more empathetic than male students towards patients although this finding was significant only among the student respondents. No participant indicated that male students were more empathetic than female students.

\section{Student-Specific Findings}

The majority of the responding students $(63.7$ percent) reported that faculty mentorship in clinics was equally available and similar in content for male and female dental students (Table 1). The remaining responses were almost equally split between mentoring being perceived as less available for female students $(\mathrm{n}=15)$ and less available for male students $(n=14)(p<0.001)$. A somewhat different pattern was reported for student favoritism by the faculty respondents: 46.0 percent stated there was no difference by gender, but 34.2 percent perceived favoritism toward female students and 19.7 percent perceived favoritism toward male students $(p<0.001)$. Half of the students thought that faculty members tended to help "attractive" students more, regardless of gender. For treatment by the clinic staff, 42.9 percent of the students reported male students being favored, and only 5 percent reported female students being favored $(\mathrm{p}<0.001)$.

More than three-quarters of the students reported no difference in faculty expectations based on student gender; however, the remaining students thought that faculty members expected more from 


\section{Table 1. Results of student survey}

\begin{tabular}{|c|c|c|c|c|c|c|}
\hline \multirow[b]{2}{*}{ Question } & \multirow{2}{*}{$\begin{array}{c}\text { Total } \\
\mathrm{N}\end{array}$} & \multicolumn{2}{|c|}{ Male } & \multicolumn{2}{|c|}{ Female } & \multirow[b]{2}{*}{ p-value } \\
\hline & & $\mathrm{N}$ & $\%$ & $\mathrm{~N}$ & $\%$ & \\
\hline $\begin{array}{l}\text { If you were to compare yourself to classmates, how would you best describe your overall confidence level in clinical } \\
\text { settings? }\end{array}$ & 84 & & & & & \\
\hline Low & & 0 & 0 & 6 & $12.2 \%$ & 0.01 \\
\hline Okay & & 9 & $25.7 \%$ & 21 & $42.9 \%$ & \\
\hline High & & 26 & $74.3 \%$ & 22 & $44.9 \%$ & \\
\hline Do you prefer to work with male or female faculty members? & 84 & & & & & \\
\hline Female & & 1 & $2.9 \%$ & 5 & $10.0 \%$ & 0.43 \\
\hline Male & & 3 & $8.8 \%$ & 6 & $12.0 \%$ & \\
\hline Makes no difference & & 30 & $88.2 \%$ & 39 & $78.0 \%$ & \\
\hline Are younger faculty members more sensitive to concerns and issues regarding gender than older faculty members? & 84 & & & & & \\
\hline Yes & & 9 & $26.5 \%$ & 23 & $46.0 \%$ & 0.21 \\
\hline No & & 4 & $11.8 \%$ & 4 & $8.0 \%$ & \\
\hline I do not think there is a difference in attitudes & & 21 & $61.7 \%$ & 23 & $46.0 \%$ & \\
\hline Do you feel there is difference in terms of respect shown towards female vs. male faculty by students? & 84 & & & & & \\
\hline No difference observed & & 33 & $97.1 \%$ & 23 & $46.0 \%$ & $<0.0001$ \\
\hline Female faculty members are less respected than male faculty & & 1 & $2.9 \%$ & 26 & $52.0 \%$ & \\
\hline Male faculty members are less respected than female faculty & & 0 & 0 & 1 & $2.0 \%$ & \\
\hline Is faculty mentorship in clinics equally available and similar in content for male and female dental students? & 84 & & & & & \\
\hline No real difference in availability or content & & 20 & $64.5 \%$ & 31 & $62.0 \%$ & $<0.0001$ \\
\hline Less available and/or different content for female students & & 1 & $3.2 \%$ & 15 & $30.0 \%$ & \\
\hline Less available and/or different content for male students & & 10 & $32.3 \%$ & 4 & $8.0 \%$ & \\
\hline $\begin{array}{l}\text { Have you personally experienced or witnessed any prejudice in action or treatment against a peer based on gender } \\
\text { while in the dental school clinical settings? }\end{array}$ & 81 & & & & & \\
\hline Yes & & 11 & $35.5 \%$ & 28 & $56.0 \%$ & 0.07 \\
\hline No & & 20 & $64.5 \%$ & 22 & $44.0 \%$ & \\
\hline $\begin{array}{l}\text { If you selected yes to the previous question about witnessing prejudice in action against a peer based on gender while } \\
\text { in the dental school clinical setting, who initiated the prejudice? }\end{array}$ & 80 & & & & & \\
\hline A full-time faculty member & & 6 & $54.5 \%$ & 11 & $39.3 \%$ & \\
\hline A part-time faculty member & & 8 & $72.7 \%$ & 15 & $53.6 \%$ & \\
\hline A graduate teaching assistant (resident) & & 6 & $54.5 \%$ & 7 & $25.0 \%$ & \\
\hline A staff member & & 0 & 0 & 7 & $25.0 \%$ & \\
\hline A peer & & 3 & $27.3 \%$ & 8 & $28.6 \%$ & \\
\hline A patient & & 4 & $36.6 \%$ & 6 & $21.4 \%$ & \\
\hline
\end{tabular}


Do faculty communicate (verbal and/or nonverbal) differently with students depending on whether they are talking to a male or female student?

$$
\text { Yes }
$$

Have you personally experienced or witnessed any form of what you perceive as unwelcome sexual advances or conduct (verbal and/or physical) from faculty?

$$
\begin{aligned}
& \text { Yes } \\
& \text { No }
\end{aligned}
$$

Do faculty show favoritism toward students based on the student's gender?
No
Yes; favoritism toward male students
Yes; favoritism toward female students

Do faculty tend to provide more help to more "attractive" students regardless of gender?

$$
\text { Yes }
$$

No

Do you feel there is a difference in the clinical abilities between your male and female classmates when comparing them at similar points in their clinical education?
No difference
Yes; female students are more capable
Yes; male students are more capable

Do male or female faculty members expect "more" from the students depending on the gender of the student? No difference

Yes; they expect more from male students

Yes; they expect more from female students

Do clinical staff (assistants, clerk, etc.) treat male and female students the same?

Yes

No; they favor male students

No; they favor female students

Are male or female students more empathetic toward patients?

No difference

Male students are more empathetic

Female students are more empathetic

Do you perceive patients have a preference pertaining to the gender of their student provider?

No difference noted

Prefer male providers

Prefer female providers

$26 \quad 83.9 \% \quad 39-79.6 \%$

$\begin{array}{llll}5 & 16.1 \% & 10 & 20.4 \%\end{array}$

78

$12-40.0 \% \quad 22-45.8 \%$

$18 \quad 60.0 \% \quad 26 \quad 54.2 \%$

78

28

$2 \quad 6.7 \% \quad 4 \quad 8.3 \%$

$28 \quad 93.3 \% \quad 44 \quad 91.7 \%$

0.99

$10 \quad 34.5 \% \quad 25 \quad 53.2 \%$

$<0.0001$

77

$\begin{array}{cccc}1 & 3.4 \% & 14 & 29.8 \% \\ 18 & 62.1 \% & 8 & 17.0 \%\end{array}$

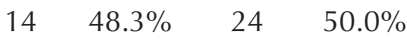

$15 \quad 51.7 \% \quad 24 \quad 50.0 \%$

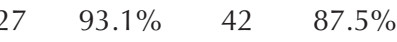

$\begin{array}{llll}0 & 0 & 0 & 0\end{array}$

$6.9 \% \quad 6 \quad 12.5 \%$

0.70

$$
\begin{array}{cccc}
72.4 \% & 39 & 81.3 \% \\
8 & 27.6 \% & 9 & 18.7 \% \\
0 & 0 & 0 & 0
\end{array}
$$

77

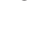

$35.4 \%$ $60.4 \%$

$\begin{array}{cccc}4 & 13.8 \% & 29 & 60.4 \% \\ 2 & 6.9 \% & 2 & 4.2 \%\end{array}$

77

$$
75.9 \% \quad 17 \quad 35.4 \% \quad<0.0001
$$

0.63

0.88

70

$\begin{array}{cccc}0 & 0 & 0 & 0 \\ 7 & 24.1 \% & 31 & 64.6 \%\end{array}$

$2 \quad 75.9 \% \quad 33 \quad 68.7 \%$

$\begin{array}{lll}17.2 \% & 9 & 18.8 \%\end{array}$ 
male students. No respondent thought that faculty members expected more from female students. Of the twenty-two students who perceived a patient preference as to the gender of their provider, eight perceived a preference for a female provider, and fourteen perceived a preference for a male provider. In open-text comments, students had several suggestions for reducing gender bias and improving the general environment. These included enforcement of a standard dress code, education of the dental faculty and staff (including part-time personnel), and a decrease in inappropriate communications.

\section{Faculty-Specific Findings}

Overall, 88 percent of the faculty respondents reported no differences between male and female students in their willingness to accept instruction/ criticism in the clinics (Table 2). In the open-text comments, faculty members recommended role modeling and mentoring to improve awareness of gender issues and concerns. They also mentioned better enforcement of university policies and conducting gender awareness educational seminars, and they suggested increased recruitment of both younger and female faculty members.

\section{Discussion}

This study suggests that there are good reasons for both optimism and concern about the current status of women in dental education and practice. About two-thirds of the female and male students reported no gender difference in faculty mentorship, and they generally perceived faculty members to be sensitive about gender issues. One-third of these students perceived younger faculty members as more sensitive about gender concerns and issues, and almost half saw no difference. The students generally reported no gender-based preference about working with female or male faculty members and no significant differences in communication between female and male faculty members. Both male and female students seemed to perceive classmates of the opposite gender as being equally clinically competent, and neither group perceived their patients as having gender-based preference for student provider.

However, gender-based perceptions continue to shape certain aspects of the predoctoral dental experience and that of female faculty members. Even though overt sexual harassment in the dental workplace is declining, ${ }^{6} 48$ percent of the students and 15 percent of the faculty members in our study reported experiencing or witnessing gender bias in clinical settings, including 7 percent of the students who reported experiencing or witnessing unwelcome sexual advances or conduct. Other specific areas of concern included lower self-confidence among female students, a perceived lack of respect toward female faculty members, and perceived gender-based differences in communication by faculty and in treatment by clinic staff.

Gender issues in clinical medical education have been addressed for years. ${ }^{6-9}$ For example, Grant cited different perceptions of sexism in clinical medical education on the part of men and women. ${ }^{6}$ She stated that women in clinical medical education see "more discrimination towards self and others" as well as "higher ratios of subtle and covert, rather than overt, sexism." In contrast, she found that men perceive "higher rates of overt sexism" and some even report that they or male classmates have been victims of "reverse discrimination." A study by Mangus et al. in 1996 found that 47 percent of female medical students reported experiencing discrimination based on gender during their medical education. ${ }^{7}$

In our study, nearly half of the students (and 15 percent of the faculty members) reported experiencing or witnessing gender-based prejudice in the clinical setting. This is consistent with an earlier study of first- and second-year dental hygiene students, in which 13 percent reported unequal treatment based on gender. ${ }^{12}$ In the same study, 6 percent of the second-year students also reported sexual harassment by other students. In our study, one-fourth of the faculty respondents reported thinking there was not adequate awareness and insight into gender-related issues among the faculty, with significantly more female than male respondents reporting this opinion $(p=0.017)$. These results point to the need for further education for faculty members.

When asked how they would compare themselves with their classmates as related to their overall confidence level in the clinical settings, significantly more female than male students in our study thought themselves less confident $(p=0.011)$. This is congruent with findings of heightened stress in general and less confidence in particular among female versus male Greek dental students participating in a longitudinal study. ${ }^{14}$ Among medical students, female students with less confidence in their own knowledge have been found to identify less with the role of doctor than those with more confidence ${ }^{15}$ Confidence levels play a role in professional negotiations, which 
directly impact salary and benefits. Often, females are socialized to verbalize feelings, portray vulnerability, express humility, or downplay their own skills. ${ }^{15}$ Such actions may result in an appearance of lower confidence as female students may feel they must underestimate their own abilities to be considered "feminine." Moss-Racusin et al. discovered that in science there is a subtle gender bias that favors male students. ${ }^{16}$ In their study, both male and female faculty members judged a female student to be less competent and less worthy of being hired than an identical male student and also offered the female a lower starting salary and less career mentoring. Clearly, there is a cultural perception that males are more knowledgeable and capable then females, which may contribute to reduced confidence levels in females. The presence of more female faculty members may help to provide a less stressful learning atmosphere than the traditionally male-dominated dental learning environment. ${ }^{17}$

Significantly more female than male students in our study perceived a difference in terms of respect shown to female versus male faculty members by students - specifically, females being shown less respect than males $(p<0.001)$. The female faculty members themselves agreed with this perception $(p<0.001)$. These female faculty members perceived inadequate awareness of gender issues among the faculty and felt less respected than their male colleagues. This is consistent with a previous study showing an overall more hostile work environment for female versus male dental faculty members. ${ }^{18}$ This finding strongly correlates with the slow advancement of women in academics as women are less likely to be tenured or promoted than men and women faculty members earn less than their male colleagues. ${ }^{19}$ The presence of more women faculty members will lessen the intellectual and social isolation women experience; additionally, with fewer women in academia, forming networks is a challenge, and female faculty members may perceive themselves as being marginalized. ${ }^{19}$ Women faculty members also have been found less likely to be viewed as role models by male students. ${ }^{20}$

When asked whether faculty members showed favoritism towards students based on the student's gender in our study, a higher percentage of students (30.2 percent) perceived favoritism by the faculty towards female students than towards male students (17.4 percent), and a substantially higher percentage of female students thought that the male students received more favorable treatment from clinical staff $(p<0.001)$. Bickel's 2001 article noted that although male and female medical students reported almost equal satisfaction with the quality of their medical education on their graduation questionnaire, the female students were more likely to report dissatisfaction with the amount of time devoted to their instruction by faculty members. ${ }^{8}$ Students tend to measure preferential treatment in terms of time/ attention by faculty. Qualitatively, comments from female students in our study noted that their male peers were more assertive in getting faculty attention, sometimes cutting ahead of them in line to speak to their mentors.

Physical attractiveness was a subtle but recurrent theme in the perception of preferential treatment of women in particular among our participants. In qualitative comments, there were numerous comments that some female students used their physical attributes and style of dress to curry favor with male faculty members (data not shown). In contrast, female students tended to note their male peers' assertive behavior and "good old boy" status used to good advantage with male faculty members. At least half of all students saw attractive students of either gender as receiving preferential treatment.

There is nothing in the current literature relating to staff-student gender issues in dentistry; however, the fact that our survey found this to be a statistically significant issue points to the need for gender issue education for dental school staff. A study in medicine that looked at doctor-nurse relationships when both are female reported that female doctors often found they were met with less respect and confidence and were given less help than their male colleagues. ${ }^{21}$ One interpretation is that this was done to reduce the status differences between the two groups. The strategies used by female doctors included doing as much as possible themselves and making friends with the nurses. That study also found that a younger female physician was given less assistance than an older/ experienced female physician and that male doctors regardless of age received more help and engaged in "erotic games" with the female nurses.

Another statistically significant finding from our student survey was that female students were perceived to be more empathetic in their patient care than were male students $(p<0.0001)$. Another study found that female dentists were perceived to be significantly more likely to make patients feel relaxed and to take time to discuss ailments with them. ${ }^{22}$ These findings are not specific to dental schools since age/generational differences and gender continue to shape perceptions in the broader culture and 


\section{Table 2. Results of faculty survey}

\begin{tabular}{|c|c|c|c|c|c|c|}
\hline \multirow[b]{2}{*}{ Question } & \multirow{2}{*}{$\begin{array}{c}\text { Total } \\
\mathrm{N}\end{array}$} & \multicolumn{2}{|c|}{ Male } & \multicolumn{2}{|c|}{ Female } & \multirow[b]{2}{*}{ p-value } \\
\hline & & $\mathrm{N}$ & $\%$ & $\mathrm{~N}$ & $\%$ & \\
\hline Number of half days of clinical teaching in your typical week: & 33 & & & & & \\
\hline $1-3$ half days & & 14 & $56.0 \%$ & 5 & $62.5 \%$ & 1.000 \\
\hline 4 or more half days & & 11 & $44.0 \%$ & 3 & $37.5 \%$ & \\
\hline
\end{tabular}

Do you prefer to work with male or female students?

Female

Male

Makes no difference

Do you feel there is appropriate awareness and insight into issues regarding gender among faculty? Yes

No

Have you personally witnessed any prejudice in action or treatment of students by faculty while in the dental school clinical setting that you perceived to be based on gender?

Yes No

Do you feel there is a difference in terms of respect shown towards female versus male faculty by students? No difference observed

Female faculty members are less respected than male faculty Male faculty members are less respected than female faculty

Do you communicate (verbal/nonverbal) differently with students depending on whether you are talking to male or female students?

No difference

Yes, I communicate differently depending on the gender of the student

Have you personally witnessed any form of what you perceive as unwelcome sexual advances or conduct (verbal or physical) by faculty toward students?

Yes

No

34

$\begin{array}{cccc}0 & 0 & 0 & 0 \\ 0 & 0 & 0 & 0 \\ 25 & 100 \% & 9 & 100 \%\end{array}$

22

$\begin{array}{lll}88.0 \% & 4 & 44.4 \% \\ 12.0 \% & 5 & 55.6 \%\end{array}$

Do you perceive there is a difference in the clinical abilities of male and female dental students when comparing them at similar points in their clinical education?

No; male and female students have similar clinical abilities

Yes; male students in general (on average) have better clinical abilities

Yes; female students in general (on average) have better clinical abilities

Is there a difference in the empathy shown to patients based on the gender of the students? No difference

Yes; male students are more empathetic

Yes; female students are more empathetic

$\begin{array}{cccc}24 & 96.0 \% & 8 & 88.9 \% \\ 0 & 0 & 0 & 0 \\ 1 & 4.0 \% & 1 & 11.1 \% \\ & & & \\ 15 & 60.0 \% & 6 & 66.7 \% \\ 0 & 0 & 0 & 0 \\ 10 & 40.0 \% & 3 & 33.3 \%\end{array}$




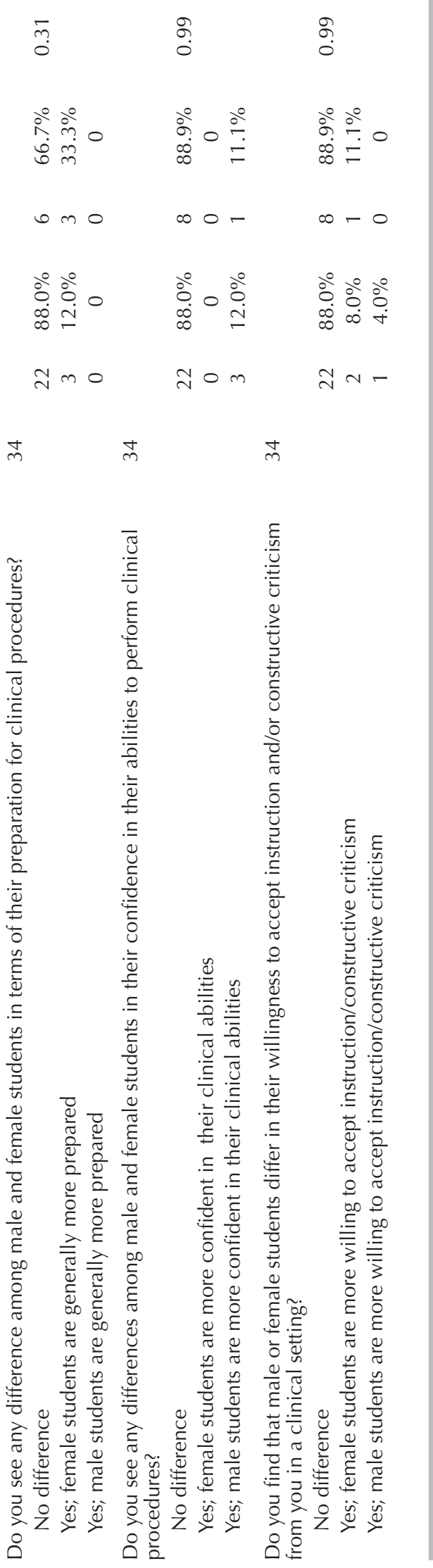

society, which are then reflected in its institutions. This may help account for the different perceptions of gender-based discrimination reported by female faculty versus female students in our study. Changing definitions of socially acceptable attitudes towards gender and ethnicity over recent decades also may be influencing a "socially desirable response" on questionnaires such as ours. In the qualitative comments of some students, there emerged a tense, irritable, and sometimes resentful (even angry) tone not evident in the statistical results.

\section{Limitations and Future Directions}

There were several limitations to this study. Although we discovered a number of statistically significant findings, the response rates were lower than desired, particularly among students (36.4 percent), despite sending out multiple requests for participation. This low rate was likely the result of timing the survey close to graduation. For the faculty survey, it would have been a good idea to include part-time faculty participation. Additionally, future studies would benefit by including questions that were recurring themes in the qualitative statements of our study.

As with all surveys, the subjectivity of the responses might not accurately reflect the current dental education environment. The issues examined in our study should be explored in other larger populations of students and faculty members at both private and public institutions. With generation of a firm empirical knowledge base, corrective interventions could then be designed and implemented for the clinic component of dental education. It is evident from this study that there continue to be some issues with gender equality in clinical education, and it would be ideal for schools to create a mechanism for which these issues can be identified and addressed.

Finally, gender issues related to other aspects of dental education need to be further explored. Although the strength of our study was hampered by the sample size and is limited to a single dental school, it does contribute to the limited amount of research in the area of gender issues in clinical dental education. This study points to the need to develop more research in this area since it supports the notion that issues do exist and our statistically significant findings have been well documented in 
other educational disciplines. We suggest that the American Dental Education Association (ADEA) is an appropriate organization to further investigate gender issues in dental education through seminars, forums, and work groups.

\section{Conclusion}

This study suggests that there are gender issues and concerns among both dental students and faculty members. However, until the results of this study are confirmed elsewhere, the generalizability of the findings is a concern. In order to decrease the concerns raised by students and female faculty respondents at our institution, our recommendations include better enforcement of university policies, mandatory gender awareness seminars for staff and part-time faculty, and increased recruitment of younger and more female faculty members. A more extensive study including more qualitative data would help validate these findings and shed more light on some of the subtle but important undercurrents in the conversation about the role of gender in dental education. Given that any level of gender-related discrimination is unacceptable, dental educators should take steps to ensure that equal treatment is provided to all students.

\section{Acknowledgments}

Support for this research project was provided by an unrestricted grant from the ADEAGies Foundation and the ADEA Center for Equity and Diversity.

\section{REFERENCES}

1. Sinkford JC, Valachovic RW, Harrison S. Advancement of women in dental education: trends and strategies. J Dent Educ 2003;67(1):79-83.

2. American Dental Association Survey Center. 2010-11 survey of dental education: academic programs, enrollment, and graduates, vol. 1, 2012. At: www.ada.org/ sections/professionalResources/pdfs/survey_ed_vol1.pdf. Accessed: October 8, 2012.

3. American Dental Association Survey Center. Distribution of dentists in the United States by region and state, 2009. At: www.ada.org/members/sections/professionalResources/09_dod.pdf. Accessed: October 8, 2012.

4. Solomon ES. Women in academic dentistry: a profile. J Am Coll Dent 1991;58(3):27-32.

5. Collins MA, Zinskie CD, Keskula DR, Thompson AL. Characteristics of full-time faculty in baccalaureate dental hygiene programs and their perceptions of the academic work environment. J Dent Educ 2007;71(11):1385-402.
6. Grant L. The gender climate of medical school: perspectives of women and men students. J Am Med Womens Assoc 1988;43(4):109-10,115-9.

7. Mangus RS, Hawkins CE, Miller MJ. Prevalence of harassment and discrimination among 1996 medical school graduates: a survey of eight US schools. JAMA 1998;280(9):851-3.

8. Bickel J. Gender equity in undergraduate medical education: a status report. J Womens Health Gend Based Med 2001;10(3):261-70.

9. Carr PL, Ash AS, Friedman RH, et al. Faculty perceptions of gender discrimination and sexual harassment in academic medicine. Ann Intern Med 2000;132(11):889-96.

10. Rosenberg HM, Cucchiara AJ, Helpin ML. Dental students' attitude to gender roles. Soc Sci Med 1998;47(11):1877-80.

11. Scarbecz M, Ross JA. The relationship between gender and postgraduate aspirations among first- and fourth-year students at public dental schools: a longitudinal analysis. J Dent Educ 2007;71(6):797-809.

12. Warren DP, Henson HA, Turner SD, O'Neill PN. Diversity, cultural sensitivity, unequal treatment, and sexual harassment in a school of dental hygiene. J Dent Hyg 2004;78(4):9.

13. Stewart DW, Shamdasani P, Rook D. Focus groups: theory and practice. In: Applied research in social psychology. Beverly Hills: Sage, 1990:53-4.

14. Polychronopoulou A, Divaris K. A longitudinal study of Greek dental students' perceived sources of stress. J Dent Educ 2010;74(5):524-30.

15. Blanch DC, Hall JA, Roter DL, Frankel RM. Medical student gender and issues of confidence. Patient Educ Couns 2008;72:374-81.

16. Moss-Racusin CA, Dovidio JF, Brescoll VL, et al. Science faculty's subtle gender biases favor male students. Proc Nation Acad Sci U S A 2012;109(41):16474-9.

17. Yuan JCC, Kaste LM, Lee DJ, et al. Dental student perceptions of predoctoral implant education and plans for providing implant treatment. J Dent Educ 2010;75(6): 750-60.

18. Nesbitt PE, Inglehart MR, Sinkford JC. Work environment perceptions of full-time dental educators: does gender matter? J Dent Educ 2003;67(8):916-24.

19. Winker JA. Women in geography in the $21^{\text {st }}$ century: faculty reappointment, tenure, and promotion barriers for women. Prof Geographer 2000;52(4):737-50.

20. Onyebuchi AA, Heineman MJ, Lombarts K. Factors influencing residents' evaluations of clinical faculty member teaching qualities and role model status. Med Educ 2012;46:381-9.

21. Gjerberg E, Kjolsrod L. The doctor-nurse relationship: how easy is it to be a female doctor co-operating with a female nurse? Soc Sci Med 2001;52:189-202.

22. Smith MK, Dundes L. The implications of gender stereotypes for the dentist-patient relationship. J Dent Educ 2008;72(5):562-70. 